\title{
Van der Woude Syndrome
}

National Cancer Institute

\section{Source}

National Cancer Institute. Van der Woude Syndrome. NCI Thesaurus. Code C74986.

A rare autosomal dominant syndrome caused by mutations in the IRF6 gene. It is characterized by a cleft palate and/or pits on the lower lip. Other signs and symptoms include absent teeth, palate and tongue deformities. 